\title{
Room temperature spallation of $\alpha$-alumina films grown by oxidation
}

\author{
S. Wang, C. M. Harvey*, B. Wang \\ Department of Aeronautical and Automotive Engineering, Loughborough University, \\ Loughborough, Leicestershire LE11 3TU, UK
}

\begin{abstract}
Tolpygo and Clarke (2000) presented an excellent experimental study on the room temperature circular spallation of $\alpha$-alumina films grown by oxidation on Fe-Cr-Al alloy. Their observations are remarkable and thought-provoking and are worthy of mechanical interpretation. The present work hypothesizes that pockets of energy concentration (PECs) exist due to dynamic and non-uniform plastic relaxation or creep in the film and $\mathrm{Fe}-\mathrm{Cr}-\mathrm{Al}$ alloy substrate during cooling. PECs may be the driving energy for room temperature spallation failure. Based on this hypothesis, an analytical mechanical model is developed in this work to predict the spallation behavior, including the separation nucleation, stable and unstable growth, and final spallation and kinking off. The predictions from the developed model are compared against experimental results and excellent agreement is observed. The work reveals a completely new failure mechanism of thin layer materials.
\end{abstract}

Keywords: Alumina film; Energy release rate; Pockets of energy concentration; Residual stress; Spallation

* Corresponding Author

Email addresses: S . wang@lboro . ac . uk (Simon Wang), c.m. harvey@lboro.ac.uk (Christopher M. Harvey), b.wang2@lboro . ac . uk (Bin Wang) 


\begin{tabular}{|ll|}
\hline Nomenclature & \\
$A$ & amplitude of upward deflection of film bubble \\
$G, G_{I}, G_{I I}$ & Young's modulus of film \\
$G_{I c}, G_{I I c}$ & total, mode I and mode II ERRs \\
$G_{c}$ & film-substrate pure mode I and II interface fracture toughness \\
$G_{c f}$ & fracture toughness of film \\
$h$ & thickness of film \\
$M_{r B}, N_{r B e}$ & crack tip radial bending moment and effective force \\
$r$ & radial coordinate of circular film bubble \\
$R_{B}$ & radius of circular-edged delamination \\
$U_{0}$ & strain energy of film bubble before separation \\
$U_{a}$ & bubble energy'; increase in combined strain energy and surface energy due \\
$U_{b}$ & to bubble separation \\
$U_{i}$ & bending strain energy of film bubble \\
$U_{s}$ & in-plane strain energy of film bubble \\
$w$ & surface energy of delaminated surfaces of film bubble \\
$Z$ & upward deflection of film bubble \\
$\alpha$ & out-of-plane coordinate \\
$\beta$ & buckling correction factor (e.g. due to initial imperfection) \\
$\varepsilon_{0}, \sigma_{0}$ & ank-off angle \\
$\varepsilon_{r}^{R}, \sigma_{r}^{R}$ & aniform residual compressive strain and stress in film \\
$\varepsilon_{\theta}^{R}, \sigma_{\theta}^{R}$ & averaged radial relaxation strain and stress due to bending deflection \\
$\theta$ & ratio of film-substrate pure mode II and I interface fracture toughness \\
$v$ & \\
\hline
\end{tabular}

\section{Introduction}

Tolpygo and Clarke [1,2] presented an excellent experimental study on the room temperature spallation failure of $\alpha$-alumina films grown by oxidation on Fe-Cr-Al alloy. Their observations are remarkable and thought-provoking. Refs. 1 and 2 convincingly demonstrate a thin film spallation process with an unknown mechanical mechanism. To help readers understanding the present work, a detailed introduction to Refs. 1 and 2 is thought to be necessary. In their work, $\alpha-\mathrm{Al}_{2} \mathrm{O}_{3}$ films of different thicknesses were formed on the surface of Fe-Cr-Al heat-resistant alloy substrates of different thicknesses by oxidizing them at $1200^{\circ} \mathrm{C}$ for different time periods. Then, the film-substrate material systems were cooled to room temperature at different cooling rates. Cooling causes an increase of compressive in- 
plane residual stress in the $\alpha-\mathrm{Al}_{2} \mathrm{O}_{3}$ films due to thermal expansion mismatch between the films and the substrates. Their major observations were as follows: No separation or spallation failure occurs during cooling at any rate. For specimens cooled to room temperature at rates in the range $5^{\circ}-200^{\circ} \mathrm{C} \mathrm{min}^{-1}$, circular interfacial separations develop, apparently spontaneously, at a constant compressive residual stress far below the critical buckling stress: The separations nucleate, grow in separation distance and propagate radially. After a period of slow and stable growth, some of these separations then grow abruptly and the oxide spalls off. For specimens cooled at extremely slow cooling rates $\left(\leq 2^{\circ} \mathrm{C} \mathrm{min}^{-1}\right)$ and at very fast cooling rates $\left(\geq 500^{\circ} \mathrm{C} \mathrm{min}^{-1}\right)$, no separation or spallation occurs at any point.

\subsection{Tolpygo and Clarke's proposed explanations}

Various explanations for the phenomenon were proposed and thoroughly and insightfully examined by Tolpygo and Clarke [1,2]. One category of these explanations was the flaw or imperfection hypothesis [3,4], which attempted to explain the nucleation and growth of the separations. The hypothesized flaw consisted of pre-existing separations, cavities or other large defects; or pre-existing inclusions such as Zr-containing oxides; or impurity segregations at the oxide-substrate interface due to the slow cooling rates. Each possible type of flaw was explored in turn. Optical microscopy studies showed that no discernible interfacial separations or spallation existed in any of the specimens when examined immediately after cooling to room temperature. Also, when examining the exposed metal surface after spallation, scanning electron microscopy studies did not reveal any interfacial cavities or voids except for areas near sharp edges at the periphery of the specimens. Some craters on the metal surface were formed by Zr-rich oxide particles in the film but they were largely similar in size to the film thickness. They therefore could not have provided a flaw that was large enough to result in film buckling. Furthermore, these Zr-rich oxide particles were found to resist separation propagation, maintaining stable separation and preventing spallation. Regarding impurity segregation, some impurities such as sulphur, carbon or phosphorous may be expected to segregate at the interface due to the gradual decrease of solubility of the metal during slow cooling. Little difference in segregation was found between slow and fast cooling rates however. This flaw hypothesis was therefore invalidated.

In the second hypothesis, the time-dependent growth behavior of the separations was explained by stress corrosion due to moisture [5]. To have a convincing invalidation of this hypothesis, some slowly-cooled specimens were placed in a sealed container in a purified 
nitrogen atmosphere with zero humidity. Spallation was still as prevalent as during regular exposure in ambient atmosphere [1].

Cooling rates affect the separation and spallation behavior, as shown by all the specimens. A third hypothesis, therefore, was that metal plastic strain during cooling is the key factor governing the spallation as it is directly related to the cooling rates. Carefully designed experiments, however, showed that the metal plastic strain during cooling was not sufficient to cause spallation of the film [1].

Several other hypotheses were also considered in Refs. 1 and 2: Condensation of equilibrium thermal vacancies at the interface during cooling, diffusion of hydrogen or carbon monoxide from the metal to the film causing disruption to the film at room temperature, and metal embrittlement or hardening near the interface. Tolpygo and Clarke [1], however, stated that none of these hypotheses is consistent with all the experimental results. Readers are strongly recommended to read their work [1,2] for a thorough understanding of the above descriptions. A more recent study [6] on the same topic presents some contradictory observations. A major one is that impurity segregation at the film metal interface is indeed a key factor on the separation and spallation of the film.

\subsection{A new hypothesis}

The present study is triggered by Tolpygo and Clarke's work [1,2]. It hypothesizes that pockets of energy concentration (PECs) in the film-metal material system exist due to dynamic and non-uniform plastic relaxation or creep in the film and Fe-Cr-Al alloy substrate during cooling. PECs may be the cause of film separation and spallation at constant in-plane compressive stress after cooling to room temperature. PECs are formed during cooling and are randomly distributed. Their energy depends on cooling rate, film thickness, metal thickness, etc. More details about PECs regarding their origin and the resulting bubble energy will be explained at appropriate points in the following development.

In the case of fast cooling, nearly no plastic or creep relaxation due to cooling occurs in either the oxide or the metal and the mechanical process is closely thermo-elastic [1]. Consequently it is reasonable to expect that very fast cooling results in uniform biaxial inplane compressive stress in the film and no interfacial stress except for in areas near to the edges of a specimen. In this case, therefore, there are no PECs formed in the film-metal material system, even though the film has the largest residual stress. 
In contrast, nearly complete plastic or creep relaxation will occur in both the film and the metal during extremely slow cooling. By 'complete' it is meant that plastic relaxation is steady and uniform at any temperature during cooling, and that a slower cooling rate would produce the same plastic relaxation history with respect to cooling temperature. Consequently it is reasonable to expect that extremely slow cooling also results in uniform biaxial in-plane compressive stress in the film and no interfacial stress except for in areas near to the edges of a specimen. In this case, therefore, there are also no PECs formed in the film-metal material system (with the film having the smallest residual stress).

Now it becomes clear that intermediate cooling rates are unable to produce steady and uniform plastic relaxation. The present study makes the hypothesis that the dynamic and nonuniform plastic relaxation from intermediate cooling rates results in pockets of tensile stress and shear stress on the interface and its adjacent material, with the former being dominant [1,2], while still producing uniform in-plane residual stress in the film. These pockets of stresses result in PECs and these PECs cause interface separation nucleation, growth and spallation of the film. It is seen that the energy in a PEC is essentially extra strain energy in the film-substrate material system in addition to the strain energy in the film due to the uniform biaxial in-plane compressive stress. When the separation process is regarded as the continuation of dynamic and non-uniform plastic relaxation, the time dependence of the process is apparent. This time dependence and how the PECs are formed are not, however, considered in this work.

The present work focuses on the development of an analytical mechanical model based on the PECs hypothesis to predict the spallation behavior, including the separation nucleation, stable and unstable growth, and final spallation and kinking off. The analytical development is given in Section 2. Theoretical predictions are compared with experimental results [2] in Section 3. Conclusions are given in Section 4.

\section{Analytical development}

In this section, an analytical mechanical model will be developed based on the PECs hypothesis in order to explain the separation nucleation, growth and spallation behavior of $\alpha$ alumina films from the Fe-Cr-Al alloy substrates in Tolpygo and Clarke’s work [1,2]. A brief introduction to their experimental procedure is given first to help the development.

A commercial heat-resistant alloy, Kanthal A-l, with nominal composition Fe$21.2 \% \mathrm{Cr} 5.6 \% \mathrm{Al}$ (wt.\%) was used in the experiments. The alloy was annealed in a vacuum at 
$1100^{\circ} \mathrm{C}$ for $25 \mathrm{~h}$ and cut into square plates $\left(12 \times 12 \mathrm{~mm}^{2}\right)$ with different thicknesses $(0.53 \mathrm{~mm}$, $1.05 \mathrm{~mm}, 2.00 \mathrm{~mm}$ and $2.65 \mathrm{~mm}$ ). After polishing to a 3- $\mu \mathrm{m}$ finish and cleaning in acetone, all the specimens were oxidized at $1200^{\circ} \mathrm{C}$ in ambient air for times in the range $0.5-100 \mathrm{~h}$ to give different oxide thicknesses in the range 0.5-8.0 $\mu \mathrm{m}$. After isothermal oxidation, each specimen was cooled to room temperature at a constant rate. Several cooling rates in the range $2^{\circ}-1000^{\circ} \mathrm{C} \mathrm{min}^{-1}$ were used. The separation nucleation, growth and spallation of the $\alpha$ alumina film separations from the Fe-Cr-Al alloy substrate at constant room temperature and constant residual stress were monitored using different experimental techniques. Fig. 1 shows a general view of a group of specimens cooled at different rates after $\alpha$-alumina spallation at room temperature. The randomly distributed white spots are the spallation sites. The thickness of the alloy of the specimens shown in Fig. 1 is $1.05 \mathrm{~mm}$. The oxidation time is $25 \mathrm{~h}$ at $1200^{\circ} \mathrm{C}$ in ambient air. Six cooling rates are shown. When the cooling rate is below $2^{\circ} \mathrm{C} \min ^{-1}$ no spallation observed as complete plastic relaxation is achieved at any temperature during cooling resulting in no PECs. When the cooling rate is above $500^{\circ} \mathrm{C} \mathrm{min}{ }^{-1}$ there is no spallation observed either as the cooling process is purely thermo-elastic resulting in no PECs.

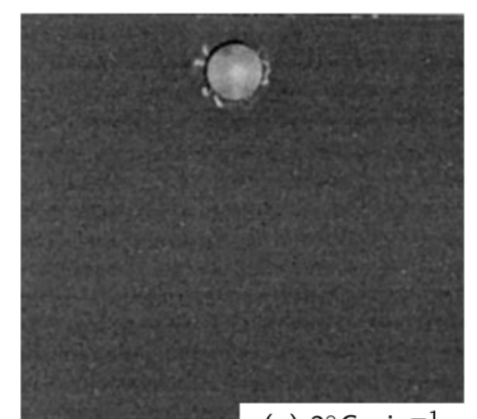

(a) $2^{\circ} \mathrm{C} \min ^{-1}$

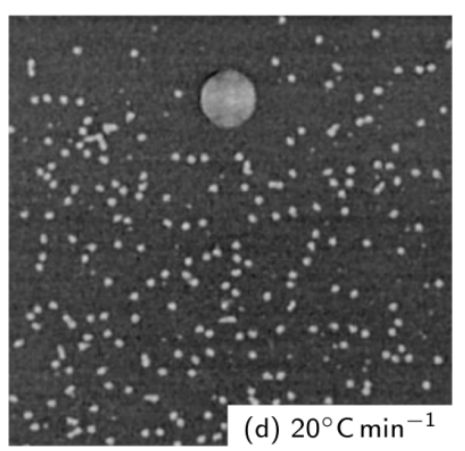

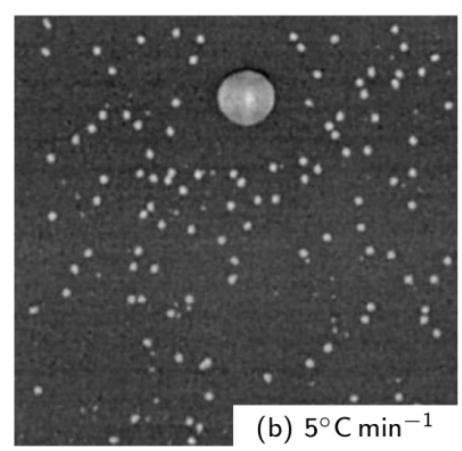

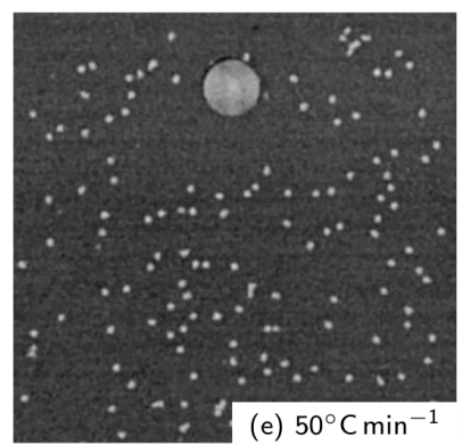

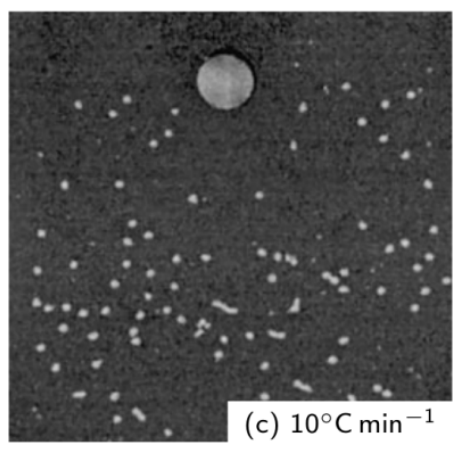

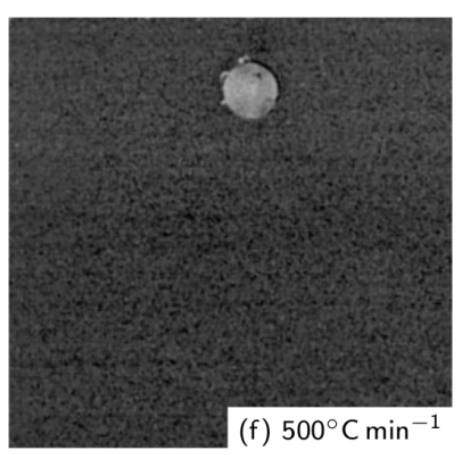

Fig. 1. General view of a group of 1.05-mm thick Kanthal samples after $25 \mathrm{~h}$ oxidation at $1200^{\circ} \mathrm{C}$ cooled to room temperature at the rates indicated. Reprinted with permission from 
Tolpygo, V.K., Clarke, D.R., 2000. Mater. Sci. Eng. A278, 142-150. Copyright 2000 Elsevier.

Fig. 2 shows a sequence of optical images illustrating the nucleation, growth and spallation of one typical separation from another specimen where the thickness of the oxide scale is about $5.0 \mu \mathrm{m}$ and the residual stress is $4.3 \mathrm{GPa}$. Figs. 2a-e show the nucleation and stable growth stages which took $22 \mathrm{~min}$. The time values were counted from when the specimen just reached room temperature from cooling. In Figs. 2a-d the radius of the nearly circular separation is far below the critical value for buckling. In Ref. 2, the separation is called an 'incipient buckle'. Here, it is called a 'separation bubble' because its radius is far too small to cause buckling, particularly in Figs. 2a-c. The abrupt growth starts after Fig. 2e and spallation failure has occurred by Fig. 2f, taking less than $1 \mathrm{~min}$. The following work aims to develop an analytical mechanical model to explain some aspects of the above observations.
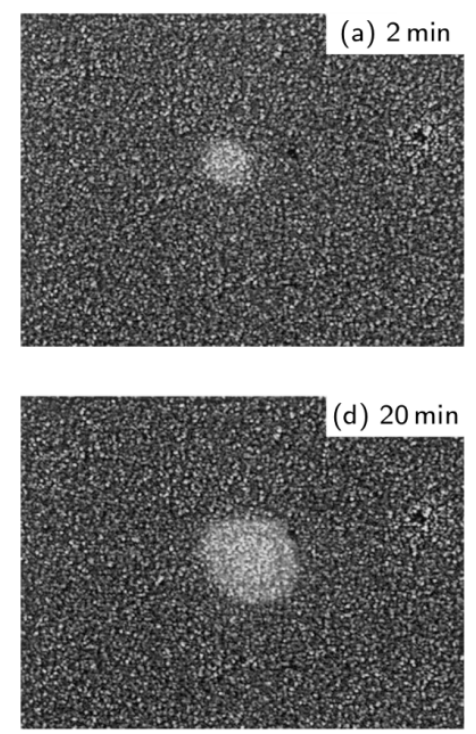
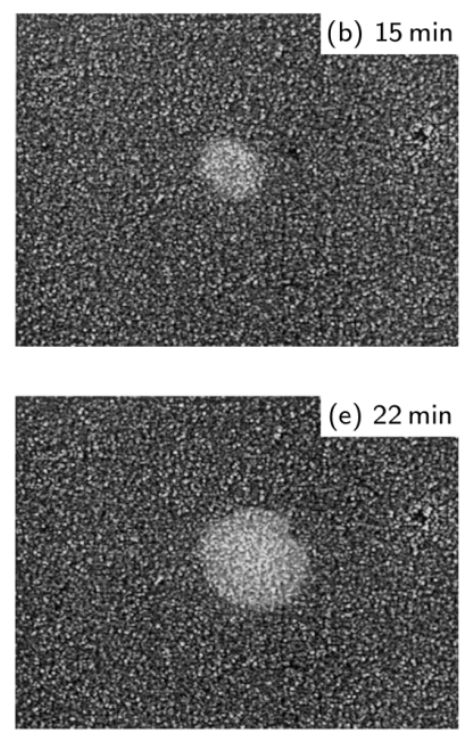
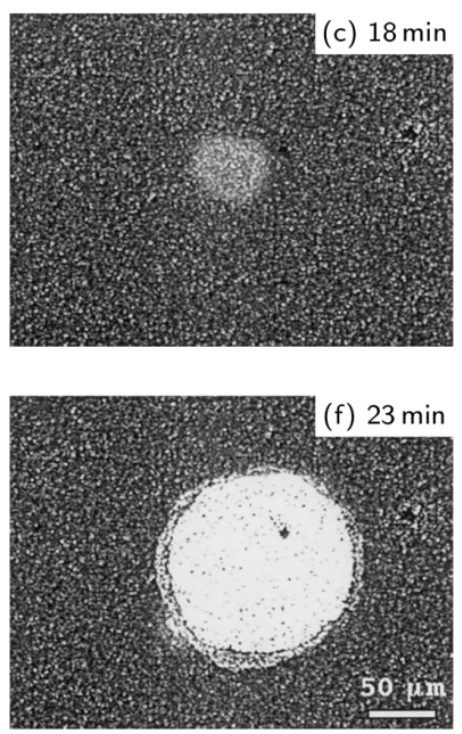

Fig. 2. A sequence of optical images showing the nucleation and growth of a separation bubble with time at room temperature leading to sudden spallation after $23 \mathrm{~min}$. The oxide thickness is about $5.0 \mu \mathrm{m}$ and the residual compressive stress in the oxide measure far away from the bubble is 4.3 GPa. Reprinted with permission from Tolpygo, V.K., Clarke, D.R., 2000. Mater. Sci. Eng. A278, 151-161. Copyright 2000 Elsevier. 


\subsection{Nucleation of a separation bubble and bubble energy}

Fig. 3 shows a circular separation bubble of radius $R_{B}$ with the subscript B representing the edge of the bubble. The oxide film has thickness $h$ and is attached to the alloy substrate outside of the separation bubble region. The nucleation of the bubble is caused by stresses on the interface and in the neighboring area due to the hypothesized incomplete plastic relaxation. The details are unclear and not considered further in present work. Once a separation bubble has nucleated, the strain energy of the stresses is freed and becomes the bottom surface energy of the bubble, the top surface energy of the alloy substrate underneath the bubble, and part of the strain energy in the bubble.

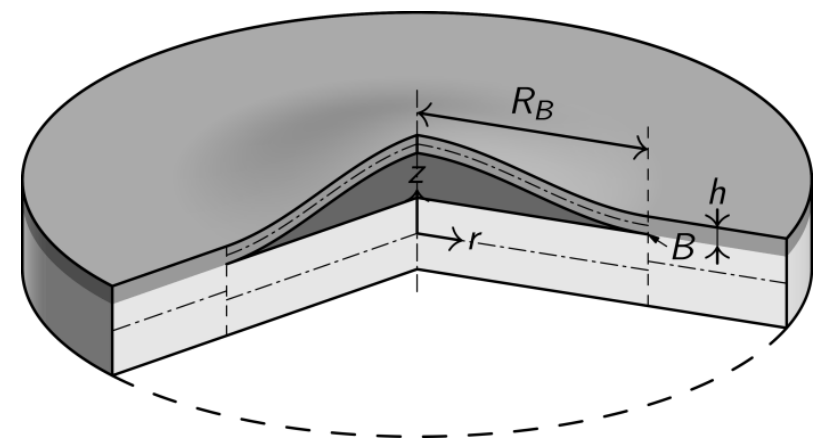

Fig. 3. A circular separation bubble of radius $R_{B}$.

In order to calculate the strain energy in the bubble, its shape is assumed to be radially sinusoidal and axisymmetric and represented by

$$
w(r)=\frac{A}{2}\left[1+\cos \left(\frac{\pi r}{R_{B}}\right)\right]
$$

with $w$ representing the upward deflection and $A$ the amplitude or the maximum separation of the oxide film from the alloy substrate. A clamped edge condition at $r=R_{B}$ is assumed because the thickness ratio between the oxide film and the alloy substrate is very small. This is shown by the data given earlier at the start of this section. It is also because the local deformation of the substrate near the interface is insignificant if the Young's modulus of substrate material is greater than a third of the film's Young's modulus [7], which applies to the present case. Based on linear elastic plate theory, the radial and circumferential bending moments are [8]

$$
M_{r}=\frac{E h^{3}}{12\left(1-v^{2}\right)}\left(\frac{d^{2} w}{d r^{2}}+\frac{v}{r} \frac{d w}{d r}\right)
$$




$$
M_{\theta}=\frac{E h^{3}}{12\left(1-v^{2}\right)}\left(\frac{1}{r} \frac{d w}{d r}+v \frac{d^{2} w}{d r^{2}}\right)
$$

The subscripts $r$ and $\theta$ represent the polar coordinates in the radial and circumferential directions respectively. $E$ and $v$ are the Young's modulus and Poisson's ratio respectively of the oxide film. Using the bending stresses arising from Eqs. (2) and (3) in conjunction with Hooke's law in polar coordinates allows the bending strain energy to be calculated as [8]

$$
U_{b}=\frac{12 \pi}{E h^{3}} \int_{0}^{R_{B}}\left(M_{r}^{2}-2 v M_{r} M_{\theta}+M_{\theta}^{2}\right) r d r
$$

with the subscript $b$ representing bending. The four equations above give

$$
U_{b}=\frac{\pi^{3}}{12} \bar{E} h^{3}\left(\frac{\pi}{4} \frac{A}{R_{B}}\right)^{2}=\frac{\pi^{3}}{12} \bar{E} h^{3} \varepsilon_{r}^{R}
$$

where $\bar{E}=E /\left(1-v^{2}\right)$ and

$$
\varepsilon_{r}^{R}=\left(\frac{\pi}{4} \frac{A}{R_{B}}\right)^{2}
$$

where $\varepsilon_{r}^{R}$ is the average elastic radial relaxation strain due to the upward deflection of the bubble. Eq. (6) is derived by using Eq. (1) and the conventional von Kármán geometric nonlinearity approach under the condition that $A / h \leq 1$, as follows:

$$
\varepsilon_{r}^{R}=\frac{1}{2 R_{B}} \int_{0}^{R_{B}}\left(\frac{d w}{d r}\right)^{2} d r=\left(\frac{\pi}{4} \frac{A}{R_{B}}\right)^{2}, \quad \varepsilon_{\theta}^{R}=0
$$

The superscript $R$ represents relaxation. When the deflection amplitude $A$ is several times the film thickness $h$, a membrane approach needs to be used. Several studies on the delamination of graphene membrane bubbles under pressure loads $[9,10]$ and point loads [11] are reported in literature, which use a membrane approach.

The average relaxation stresses in the oxide film are then easily obtained as

$$
\sigma_{r}^{R}=\bar{E} \varepsilon_{r}^{R} \quad, \quad \sigma_{\theta}^{R}=v \bar{E} \varepsilon_{r}^{R}
$$

Measurements of residual stress in some stationary buckles in Ref. 2 show that relaxation stress is much larger at the center of buckles than near to the crack tip where it is negligible. The in-plane strain energy in the film is now calculated. 


$$
\begin{aligned}
U_{i} & =\frac{\pi h R_{B}^{2}}{2}\left[\left(\sigma_{0}-\sigma_{r}^{R}\right)\left(\varepsilon_{0}-\varepsilon_{r}^{R}\right)+\left(\sigma_{0}-\sigma_{\theta}^{R}\right)\left(\varepsilon_{0}-\varepsilon_{\theta}^{R}\right)\right] \\
& =\pi h R_{B}^{2}\left[\frac{1-v}{E} \sigma_{0}^{2}-\sigma_{0} \varepsilon_{r}^{R}+\frac{\bar{E}}{2}\left(\varepsilon_{r}^{R}\right)^{2}\right]
\end{aligned}
$$

where $\sigma_{0}$ and $\varepsilon_{0}$ are the biaxial compressive residual stress and strain respectively in the original non-detached film, both of which are positive in compression. The sum of the bottom surface energy of the bubble and the surface energy of the alloy substrate underneath the bubble is calculated as

$$
U_{s}=2 \pi \int_{0}^{R_{B}} G_{c}(r) r d r=\pi R_{B}^{2} \bar{G}_{c}
$$

where $G_{c}(r)$ is the interface fracture toughness which is position-dependent because the fracture mode mixity at the crack tip may vary due to varying loading conditions at crack tip during propagation [12-17]. The fracture toughness averaged over the separated surface is denoted by $\bar{G}_{c}$. It will be shown later that $G_{c}(r)=G_{c}$ is constant, that is, $\bar{G}_{c}=G_{c}$. Collecting together $U_{b}, U_{i}$ and $U_{s}$ gives

$$
U=U_{0}+U_{a}
$$

where

$$
\begin{gathered}
U_{0}=\pi R_{B}^{2} h \frac{1-v}{E} \sigma_{0}^{2} \\
U_{a}=\pi R_{B}^{2} h \sigma_{0}\left\{\frac{1}{2 \bar{\varepsilon}_{0}}\left(\varepsilon_{r}^{R}\right)^{2}+\left[\frac{\pi^{2}}{12 \bar{\varepsilon}_{0}}\left(\frac{h}{R_{B}}\right)^{2}-1\right] \varepsilon_{r}^{R}+\frac{1}{\bar{\varphi}_{0}}\right\}
\end{gathered}
$$

in which $U_{0}$ is the strain energy only before any separation, and $U_{a}$ is the increase in the combined strain energy and surface energy due to separation, with $\bar{\varepsilon}_{0}=\sigma_{0} / \bar{E}$ and $\bar{\varphi}_{0}=h \sigma_{0} / \bar{G}_{c}$. It can be shown that $U_{a}$ is always positive and monotonically increases with respect to the relaxation strain $\varepsilon_{r}^{R}$ or the bubble amplitude $A$ when $\left(R_{B} / h\right)^{2}<\pi^{2} /\left(12 \bar{\varepsilon}_{0}\right)$. In this work, $U_{a}$ is called 'bubble energy'. It comes from the PEC energy formed in the filmmetal material system during cooling. When the PEC energy is able to provide the bubble energy $U_{a}$ for nucleation, nucleation of a separation bubble will occur. It is expected that the bubble energy $U_{a}$ governs the growth behavior of a bubble. Obviously, when the bubble 
energy disappears, that is, $U_{a}=0$, a bubble will stop growing. Details about $U_{a}$ are given during the following development, for bubble nucleation, stable growth, unstable growth, spallation and kinking off.

According to the PEC hypothesis, PEC energy is formed in the film-metal material system during cooling due to dynamic and non-uniform plastic relaxation. As the formation of PECs is not considered in detail in this work, no mathematical expression for PECs will be derived. At particular times in the process of spallation, however, the amounts of PEC energy required for nucleation of a separation bubble, for its stable and unstable growth and final spallation will be shown. They are closely related to the bubble energy $U_{a}$.

\subsection{Stable growth of a separation bubble driven by bubble energy}

The separation bubble bends away from the alloy substrate after nucleation, growing in height and producing a driving force for radial growth, that is, it produces energy release rate (ERR) at the bubble edge. When the ERR exceeds the interface fracture toughness the bubble radius grows. The total ERR $G$ is given by $[14,17]$

$$
G=\frac{6}{\bar{E} h^{3}}\left(M_{r B}^{2}+\frac{h^{2}}{12} N_{r B e}^{2}\right)
$$

where $M_{r B}$ and $N_{r B e}$ are the radial bending moment and effective radial force respectively at the crack tip. They can be readily calculated as

$$
\begin{gathered}
M_{r B}=\frac{\bar{E} h^{3}}{12}\left(\frac{d^{2} w}{d r^{2}}\right)_{r=R_{B}}=\frac{2 \bar{E} h^{3}}{3 A}\left(\frac{\pi}{4} \frac{A}{R_{B}}\right)^{2}=\frac{2 \bar{E} h^{3}}{3 A} \varepsilon_{r}^{R} \\
N_{r B e}=\left[\sigma_{0}-\left(\sigma_{0}-\sigma_{r}^{R}\right)\right]_{r=R_{B}} h=0
\end{gathered}
$$

Eq. (16) results from the fact mentioned earlier that measurements of residual stress in Ref. 2 show approximately zero relaxation stress at the crack tip. It is well known that interface fracture toughness is mode mixity-dependent and varies with different partition theories [1217]. Extensive experimental tests [12-14] have shown that the partition theory based on Euler beam or classical plate theory $[15,16]$ gives very accurate predictions of interface fracture toughness for macroscopic mixed-mode fracture while the partition theories based on Timoshenko beam theory or first-order shear-deformable plate theory $[15,16]$ and 2D elasticity [17-19] give poor predictions. The latest work [20], however, shows that the 
partition theory based on 2D elasticity [17-19] gives very accurate predictions of interface fracture toughness for nano-scale thin-film delamination. Previous studies [21-30] have shown that the bimaterial mismatch coefficient (i.e. the oscillation index of the interfacial stresses) can have significant effect on mode mixity in 2D elasticity. An analytical partition theory has been developed by the first two authors [31-33] to take the bimaterial mismatch coefficient into consideration. In Tolpygo and Clarke's work [1,2], the $\alpha$-alumina films grown by oxidation on Fe-Cr-Al alloy have Young's modulus $E=400 \mathrm{GPa}$ and Poisson's ratio $v=0.25$. The Fe-Cr-Al alloy has nominal composition $21.2 \% \mathrm{Cr} 5.6 \% \mathrm{Al}$ (wt.\%). The latest work [34] reports the elastic properties of $\mathrm{Fe}-\mathrm{Cr}-\mathrm{Al}$ alloys with various nominal compositions from ab initio calculations. The closest composition in Ref. 34 to that used Refs. 1 and 2 is $20 \% \mathrm{Cr} 10 \% \mathrm{Al}$ (at.\%) or 19.9\%Cr5.2\%Al (wt.\%) which has Young's modulus $E=266 \mathrm{GPa}$ and Poisson's ratio $v=0.27$. It is seen that the bimaterial mismatch coefficient in the present case is mainly due to Young's modulus mismatch. The authors' recent studies [31-33] suggest insignificant effect on mode mixity from this weak mismatch. Furthermore, in other recent work by the authors on graphene membrane adhesion [20], neglecting the bimaterial mismatch coefficient also gives excellent results in comparison to experimental measurements. Consequently the present study uses the partition theory based on 2D elasticity [17-19] with a zero value of bimaterial mismatch coefficient between the film and substrate for simplicity while focusing on the mechanism of $\alpha-\mathrm{Al}_{2} \mathrm{O}_{3}$ film spallation. The ERR partitions are therefore given by

$$
\begin{aligned}
G_{I} & =0.6227 \frac{6 M_{r B}^{2}}{\bar{E} h^{3}} \\
G_{I I} & =0.3773 \frac{6 M_{r B}^{2}}{\bar{E} h^{3}}
\end{aligned}
$$

Note that when mismatch coefficient is taken into consideration the two numerical factors in Eqs. (17) and (18) will be crack extension size- and mismatch coefficient-dependent [31-33]. Many previous studies [12-14,20] have shown that the following linear propagation criterion generally agrees very well with experimental results for brittle interfaces

$$
\frac{G_{I}}{G_{I c}}+\frac{G_{I I}}{G_{I I c}}=\frac{1}{G_{I c}}\left(G_{I}+\frac{G_{I I}}{\psi}\right)=1
$$


where $G_{I I c}=\psi G_{I c}$ with the ratio $\psi$ being constant, and $G_{I c}$ and $G_{I I c}$ are the pure mode I and II critical ERRs. Substituting the partitions in Eqs. (17) and (18) into Eq. (19) gives the following fracture toughness.

$$
G_{c}=\frac{\psi}{0.3773+0.6227 \psi} G_{I c}=\lambda G_{I c}
$$

where

$$
\lambda=\frac{\psi}{0.3773+0.6227 \psi}
$$

Obviously, the fracture toughness is constant due to the constant mode mixity. Eqs. (15) and (17)-(20) together give the amplitude for crack growth as

$$
\left(\frac{A}{h}\right)_{G R}^{2}=\frac{96 \bar{\varepsilon}_{0}}{\pi^{4} \varphi_{0}}\left(\frac{R_{B}}{h}\right)^{4}
$$

where $\varphi_{0}=h \sigma_{0} / G_{c}$ and the subscript GR denotes crack growth. Substituting Eq. (22) into Eqs. (7) and (8) gives the average relaxation strain and stress as

$$
\begin{aligned}
\left(\varepsilon_{r}^{R}\right)_{G R} & =\frac{6 \bar{\varepsilon}_{0}}{\pi^{2} \varphi_{0}}\left(\frac{R_{B}}{h}\right)^{2} \\
\left(\sigma_{r}^{R}\right)_{G R} & =\frac{6 G_{c}}{\pi^{2} h}\left(\frac{R_{B}}{h}\right)^{2}
\end{aligned}
$$

Note that these three quantities, $(A / h)_{G R},\left(\varepsilon_{r}^{R}\right)_{G R}$ and $\left(\sigma_{r}^{R}\right)_{G R}$, are independent of the biaxial residual stress $\sigma_{0}$. The bubble energy $U_{a}$ at crack growth can be obtained by substituting Eq. (23) into Eq. (13).

$$
\left(U_{a}\right)_{G R}=\pi R_{B}^{2} G_{c}\left\{\frac{3}{2}+\frac{6 \bar{\varepsilon}_{0}}{\pi^{2}}\left(\frac{R_{B}}{h}\right)^{2}\left[\frac{3}{\pi^{2} \varphi_{0}}\left(\frac{R_{B}}{h}\right)^{2}-1\right]\right\}
$$

The first term in Eq. (25) is the sum of the bending strain energy and surface energy while the rest is the relaxed in-plane strain energy, which is negligible if $R_{B}$ is small. The first term is therefore regarded as the nucleation energy, that is, $\left(U_{a}\right)_{N U}=1.5 \pi R_{B}^{2} G_{c}$ where $R_{B}$ is very small. It is seen that one third of the nucleation energy is used to bend the separation outwards after nucleating the interface separation using two thirds of its energy. When the 
PEC is able to provide the bubble energy $\left(U_{a}\right)_{G R}$, it will drive the nucleation and growth of a separation bubble. Two scenarios can occur: One scenario is slow and stable growth which occurs when $R_{B}$ is smaller than the critical buckling characteristic length. The other is unstable growth when $R_{B}$ reaches the critical value of the buckling characteristic length. The stable bubble then becomes an unstable buckle. The initiation of unstable growth is considered next.

\subsection{Initiation of unstable growth by buckling}

During slow and stable growth, the in-plane compressive stress in the bubble $\sigma_{0}-\sigma_{r}^{R}$ reduces as its radius $R_{B}$ increases. At a certain point the following condition for the buckling of thin circular plates [35] is met:

$$
\sigma_{0}-\sigma_{r}^{R}=\bar{E} \frac{(\alpha \pi)^{2}}{12}\left(\frac{h}{R_{B}}\right)^{2}
$$

where $\alpha$ is a correction factor because the buckling occurs at an amplitude $A$ which can be considered an initial imperfection. In the present study, $\alpha$ is considered an effect of boundary conditions. Its range is therefore $0.652 \leq \alpha \leq 1.220$ with the two limits corresponding to simply-supported and clamped edge conditions respectively [17,35]. A good approximation may be the average of the extreme values, that is, $\alpha=0.936$. This value is used in the present study. Note that $\sigma_{0}$ is positive in compression. By using Eqs. (24) and (26), the initiation of unstable growth, which is assumed to coincide with the buckling condition, is found at

$$
\left(\frac{R_{B}}{h}\right)_{U G}^{2}=\frac{\pi^{2} \varphi_{0}}{12}\left[1-\left(1-\frac{\alpha^{2}}{\Omega}\right)^{1 / 2}\right]
$$

with the subscript UG denoting the initiation of unstable growth and where

$$
\Omega=\frac{1}{2} \bar{\varepsilon}_{0} \varphi_{0}=\frac{h \sigma_{0}{ }^{2}}{2 \bar{E} G_{c}}
$$

Note that the negative sign in front of $\left(1-\alpha^{2} / \Omega\right)^{1 / 2}$ in Eq. (27) is chosen to meet the physical requirement that Eq. (27) gives the buckling solutions $\left(R_{B} / h\right)^{2}=(0.652 \pi)^{2} /\left(12 \bar{\varepsilon}_{0}\right)$ for the simply-supported edge condition and $\left(R_{B} / h\right)^{2}=(1.220 \pi)^{2} /\left(12 \bar{\varepsilon}_{0}\right)$ for the clamped edge 
condition. There is no unstable growth when $\Omega<\alpha^{2}$. Expansion of the expression in the square bracket in Eq. (27) for $\Omega>>\alpha^{2}$, leads to

$$
\left(\frac{R_{B}}{h}\right)_{U G}^{2}=\frac{(\alpha \pi)^{2}}{12 \bar{\varepsilon}_{0}}
$$

Substituting Eq. (29) into Eqs. (22), (23) and (24), and use of Eq. (28) where appropriate, results in Eqs. (30), (31) and (32), respectively.

$$
\begin{gathered}
\left(\frac{A}{h}\right)_{U G}^{2}=\frac{\alpha^{4}}{3 \Omega} \\
\left(\varepsilon_{r}^{R}\right)_{U G}=\frac{\alpha^{2}}{2 \varphi_{0}} \\
\left(\sigma_{r}^{R}\right)_{U G}=\frac{\alpha^{2} \bar{E}}{2 \varphi_{0}}=\frac{\alpha^{2} G_{c} \bar{E}}{2 h \sigma_{0}}=\frac{\alpha^{2} \sigma_{0}}{4 \Omega}
\end{gathered}
$$

The bubble energy at the onset of unstable growth when $\Omega>\alpha^{2}$ is obtained by substituting Eq. (29) into Eq. (25) and using Eq. (28).

$$
\left(U_{a}\right)_{U G}=\pi R_{B}^{2} G_{c}\left(\frac{3-\alpha^{2}}{2}+\frac{\alpha^{4}}{16 \Omega}\right) \approx \frac{3-\alpha^{2}}{2} \pi R_{B}^{2} G_{c} \approx \frac{\left(3-\alpha^{2}\right) \alpha^{2} \pi^{3} h^{2} G_{c}}{24 \bar{\varepsilon}_{0}}
$$

\subsection{Unstable growth and spallation of the buckle driven by buckling and bubble energy}

Since the bubble energy $U_{a}$ governs the growth behavior of the separation, the variation of bubble energy at growth $\left(U_{a}\right)_{G R}$ in Eq. (25) is considered. By differentiating $\left(U_{a}\right)_{G R}$ in Eq. (25) with respect to $R_{B} / h$, its maximum is found to occur at

$$
\left(\frac{R_{B}}{h}\right)_{M U}^{2}=\frac{\pi^{2} \varphi_{0}}{9}\left[1-\left(1-\frac{9}{8 \Omega}\right)^{1 / 2}\right]
$$

with the subscript MU denoting the maximum $\left(U_{a}\right)_{G R}$. Note that the negative sign in front of $(1-9 /(8 \Omega))^{1 / 2}$ in Eq. (34) is chosen to obtain the maximum $\left(U_{a}\right)_{G R}$. When $\Omega<9 / 8$ there is no solution. Expansion of the expression in the square bracket in Eq. (34) for $\Omega>>9 / 8$, leads to 


$$
\left(\frac{R_{B}}{h}\right)_{M U}^{2}=\frac{\pi^{2}}{8 \bar{\varepsilon}_{0}}
$$

Substituting Eq. (35) into Eqs. (22), (23) and (24), and use of Eq. (28) where appropriate, results in Eqs. (36), (37) and (38), respectively.

$$
\begin{gathered}
\left(\frac{A}{h}\right)_{M U}^{2}=\frac{3}{4 \Omega} \\
\left(\varepsilon_{r}^{R}\right)_{M U}=\frac{3}{4 \varphi_{0}} \\
\left(\sigma_{r}^{R}\right)_{M U}=\frac{3 \bar{E}}{4 \varphi_{0}}=\frac{3 G_{c} \bar{E}}{4 h \sigma_{0}}=\frac{3 \sigma_{0}}{8 \Omega}
\end{gathered}
$$

Note that $\left(R_{B}\right)_{M U}$ in Eq. (35) is approximately equal to $\left(R_{B}\right)_{U G}$ in Eq. (29) with $\alpha=1.22$ for a circular buckle with a clamped edge condition. Substituting Eq. (35) into Eq. (25) gives the bubble energy when $\Omega>>9 / 8$ as

$$
\left(U_{a}\right)_{M U}=\pi R_{B}^{2} G_{c}\left(\frac{3}{4}+\frac{9}{64 \Omega}\right) \approx \frac{3}{4} \pi R_{B}^{2} G_{c}=\frac{3 \pi^{3} h^{2} G_{c}}{32 \bar{\varepsilon}_{0}}
$$

More importantly, $\left(U_{a}\right)_{G R}$ becomes zero at

$$
\left(\frac{R_{B}}{h}\right)_{S P}^{2}=\frac{\pi^{2} \varphi_{0}}{6}\left\{1-\left[1-\frac{3}{2 \Omega}\right]^{1 / 2}\right\}
$$

Note that the negative sign in front of $(1-3 /(2 \Omega))^{1 / 2}$ in Eq. (40) is chosen to obtain the smaller value of $R_{B} / h$ at which the bubble energy becomes zero. When $\Omega<3 / 2$ there is no solution. Expansion of the expression in the square bracket in Eq. (40) for $\Omega>>3 / 2$, leads to

$$
\left(\frac{R_{B}}{h}\right)_{S P}^{2}=\frac{\pi^{2}}{4 \bar{\varepsilon}_{0}}
$$

Substituting Eq. (41) into Eqs. (22), (23) and (24), and use of Eq. (28) where appropriate, results in Eqs. (42), (43) and (44), respectively.

$$
\left(\frac{A}{h}\right)_{S P}^{2}=\frac{3}{\Omega}
$$




$$
\begin{gathered}
\left(\varepsilon_{r}^{R}\right)_{S P}=\frac{3}{2 \varphi_{0}} \\
\left(\sigma_{r}^{R}\right)_{S P}=\frac{3 \bar{E}}{2 \varphi_{0}}=\frac{3 G_{c} \bar{E}}{2 h \sigma_{0}}=\frac{3 \sigma_{0}}{4 \Omega}
\end{gathered}
$$

At this moment the unstable growth stops as there is no driving energy; however, if the kinetic energy due to fast unstable growth of the buckle is large enough to break the film at its edge, the buckle spalls. The subscript SP in the equations above denotes spallation.

A sketch of the variation of $\left(U_{a}\right)_{G R}$ for $\Omega>3 / 2$ is now given in Fig. 4 . The bubble energy $\left(U_{a}\right)_{G R}$, given by Eq. (25), increases with radial growth up to $\left(R_{B}\right)_{M U}$, given by Eq. (34) and approximately by Eq. (35). This increase comes from the PEC. Because of the increasing nature of the bubble energy $\left(U_{a}\right)_{G R}$ in this region, the growth is expected to be generally slow and steady, even in the first range of unstable growth, that is, in the range $\left(R_{B}\right)_{U G} \leq R_{B} \leq\left(R_{B}\right)_{M U}$. Unstable growth starts at $\left(R_{B}\right)_{U G}$, given by Eq. (27) and approximately by Eq. (29). In the first region of unstable growth, the radius grows by a factor of about $\left(R_{B}\right)_{M U} /\left(R_{B}\right)_{U G}=1.5^{0.5} / \alpha \approx 1.31$ where Eqs. (35) and (29) are used, and the amplitude by a factor of about $(A)_{M U} /(A)_{U G}=3 /\left(2 \alpha^{2}\right) \approx 1.71$ where Eqs. (36) and (30) are used. When the PEC is too weak to provide the bubble energy, the bubble will stop growing, even in the first unstable growth range, and then the PEC energy equals the bubble energy $\left(U_{a}\right)_{G R}$.

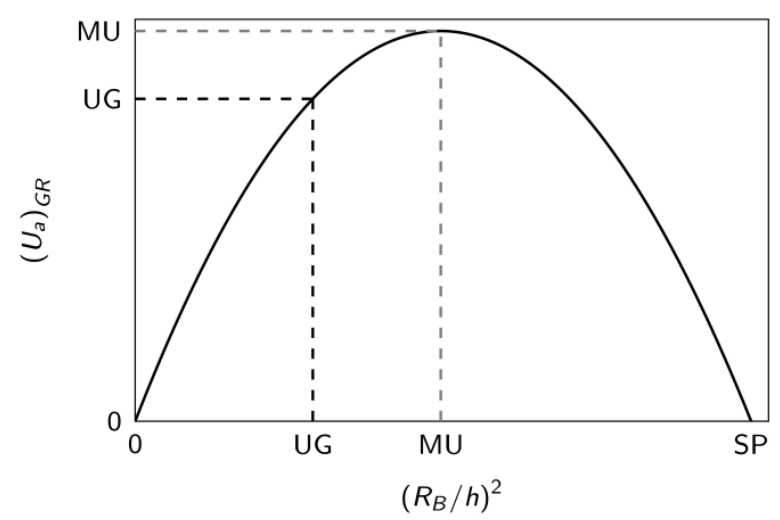

Fig. 4. The variation of $\left(U_{a}\right)_{G R}$ with respect to $\left(R_{B} / h\right)^{2}$. 
The bubble energy $\left(U_{a}\right)_{G R}$ decreases with radial growth after $\left(R_{B}\right)_{M U}$ and reduces to zero at $\left(R_{B}\right)_{S P}$, given by Eq. (40) and approximately by Eq. (41). This decreasing nature has two meanings. The first is that the bubble is no longer able to store any further bubble energy from the PEC. The second is that the bubble energy $\left(U_{a}\right)_{M U}$, cumulated in the range $0 \leq R_{B} \leq\left(R_{B}\right)_{M U}$, is being transformed into kinetic energy. This is consistent with the fact that the bifurcation-type buckling occurs at around $\left(R_{B}\right)_{M U}$, resulting in more 'violent' growth after $\left(R_{B}\right)_{M U}$. In this second region of unstable growth, that is, in the range $\left(R_{B}\right)_{M U} \leq R_{B} \leq\left(R_{B}\right)_{S P}$, the radius grows by a factor of about $\left(R_{B}\right)_{S P} /\left(R_{B}\right)_{M U}=\sqrt{2} \approx 1.41$ where Eqs. (41) and (35) are used, and the amplitude by a factor of about $(A)_{S P} /(A)_{M U}=2$ where Eqs. (42) and (36) are used. It is seen that the cracked area at $\left(R_{B}\right)_{S P}$ is twice that at $\left(R_{B}\right)_{M U}$. Obviously, the bubble will stop growth at $\left(R_{B}\right)_{S P}$ as the bubble energy becomes zero. The minimum kinetic energy can be estimated as $\left(U_{a}\right)_{M U}$ in Eq. (39) by assuming that the PEC boundary ends at $\left(R_{B}\right)_{M U}$ resulting in no further contribution to the kinetic energy. Under this assumption, the maximum PEC energy is given by $\left(U_{a}\right)_{M U}$. When $\left(U_{a}\right)_{M U}$ is large enough to break the oxide film, then spallation occurs, that is, the interface crack kinks into the oxide film. The kink-off angle $\beta$ is measured from the interface as shown in Fig. 5.

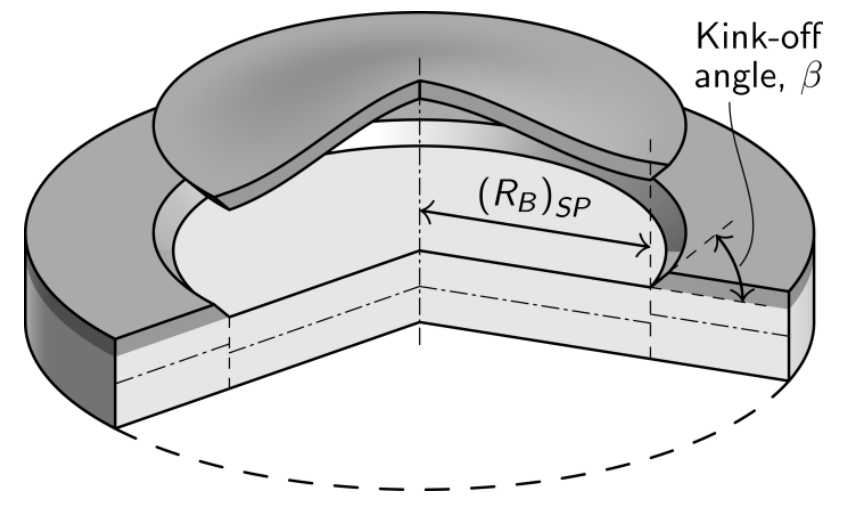

Fig. 5. The kink-off angle of a spalled oxide film.

The kink-off angle can be determined using

$$
\frac{3}{4} \pi\left(R_{B}\right)_{M U}^{2} G_{c}=\frac{2 \pi\left(R_{B}\right)_{S P} h}{\sin (\beta)} G_{c f}
$$


where $G_{c f}$ is the fracture toughness of the oxide film. Note that the left-hand side of Eq. (45) comes from Eq. (39) and the right-hand side is the breaking surface energy of the oxide film as shown in Fig.5. The kink-off angle is then obtained from Eq. (45) as follows, after substituting $\left(R_{B}\right)_{M U}$ and $\left(R_{B}\right)_{S P}$ from Eqs. (35) and (41) respectively:

$$
\beta=\arcsin \left(\frac{32}{3 \pi} \frac{G_{c f}}{G_{c}}\left(\bar{\varepsilon}_{0}\right)^{1 / 2}\right)
$$

In the next section, predictions from the developed model are compared against experimental observations from Refs. 1 and 2.

\section{Experimental comparisons}

The material properties of the oxide film are taken from Refs. 1 and 2 and are as follows: The Young's modulus of the oxide film is $E=400 \mathrm{GPa}$ and the Poisson's ratio is $v=0.25$. The mode I critical ERR of the interface is $G_{I c}=8.6 \mathrm{~N} / \mathrm{m}$ and the critical mode I ERR of the oxide film is $G_{c f}=20 \mathrm{~N} / \mathrm{m}$. The ratio $\psi=G_{\text {IIc }} / G_{\text {Ic }}=5$ is used, which, based on Ref. 36, is considered by the authors to be a representative value. Hence, Eq. (20) gives the value of $G_{c}$, i.e. $G_{c}=12.3 \mathrm{~N} / \mathrm{m}$.

In the first group of comparisons, Eq. (27) or (29) is used to predict the initial radius of unstable growth, and Eq. (40) or (41) is used to predict the size of spallation. These predictions are compared with experimental data from Ref. 2. The solid dots in Fig. 6 represent a series of measurements of the size of individual separations as a function of time at room temperature. The time of 0 min corresponds to the moment when the specimen was placed under the microscope and its temperature was close to ambient. 
(a)

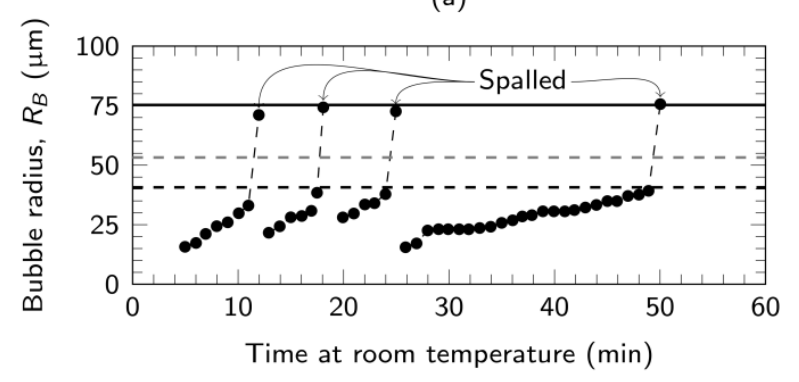

(b)

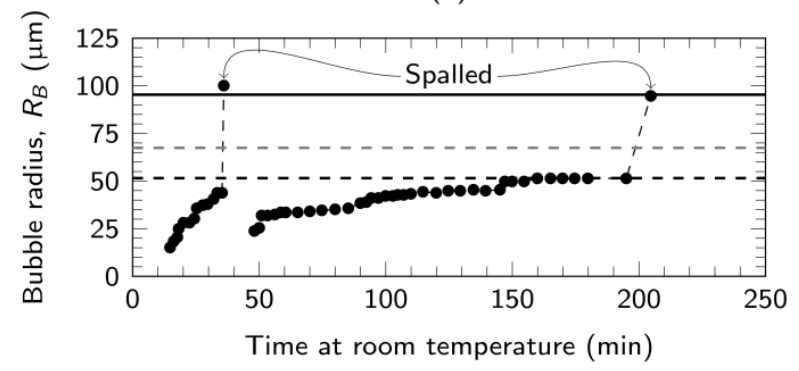

(c)

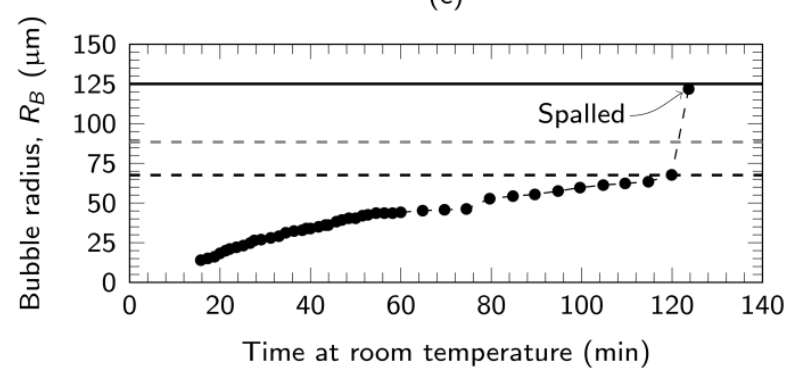

$\begin{array}{ll}\text { - - - Test data [2] } & ---\left(R_{B}\right)_{U G} \text { from Eq. (29) } \\ \text { - - - }\left(R_{B}\right)_{M U} \text { from Eq. (35) } & -\left(R_{B}\right)_{S P} \text { from Eq. (41) }\end{array}$

Fig. 6. Separation bubble radius versus time at room temperature for three different samples: (a) $h=4.9 \mu \mathrm{m}$ and $\sigma_{0}=4.46 \mathrm{GPa}$. (b) $h=6.2 \mu \mathrm{m}$ and $\sigma_{0}=4.45 \mathrm{GPa}$. (c) $h=8.0 \mu \mathrm{m}$ and $\sigma_{0}=4.31 \mathrm{GPa}$.

Fig. 6a shows data from four different separation bubbles on a single specimen after isothermal oxidation for $25 \mathrm{~h}$ at $1200^{\circ} \mathrm{C}$ and cooling at $20^{\circ} \mathrm{C} \mathrm{min}{ }^{-1}$. The bubbles were successively monitored using optical microscopy. All of the bubbles grew at a constant compressive stress of $\sigma_{0}=4.46 \pm 0.4 \mathrm{GPa}$, which was measured in the adherent oxide far away from the separations. The whole process includes nucleation, stable growth, unstable growth, and final spallation. The nucleation of separation bubbles was not recorded due to the difficulty of making timely observations of nucleating bubbles using this monitoring technique. Stable growth, however, with a radius far smaller than the critical buckling value, was readily observed. At a certain critical radius, given by Eq. (29), which is again far 
smaller than the critical buckling radius with a clamped edge condition, approximately given by Eq. (35), unstable growth abruptly occurs. It is pertinent that all four separations start unstable growth at approximately the same radius, and then all eventually spall off also at approximately the same radius.

The two specimens with thicker oxide layers were produced with $50 \mathrm{~h}$ and $100 \mathrm{~h}$ of oxidation and are shown in Figs. 6b and c respectively. The growth behaviors of two separation bubbles are shown in Fig. 6b. Again, the two separations start unstable growth at approximately the same radius, and then both eventually spall off also at approximately the same radius. Fig. 6c shows the growth behavior of one separation bubble.

The numerical values of the present prediction are also recorded in Table 1 . The values of $\Omega$ are 9.27, 11.7 and 14.1 for Figs. 6a, b and c respectively, which are much larger than $\alpha^{2}=0.936^{2}=0.876$ in Eq. (27). Eqs. (27) and (29) therefore predict very similar results for the initiation of unstable growth. Also, the $\Omega$ values are much larger than 1.5 as required by Eq. (41). Eqs. (40) and (41) therefore predict very similar results for the size of spallation. The three horizontal lines in Figs. 6a, b and c represent the predictions from Eqs. (29), (35) and (41). It is very impressive to see that the predictions of present mechanical model have excellent agreement with the test results, suggesting that the underpinning assumption of zero bimaterial mismatch coefficient is a good one.

Table 1. Comparison of the present mechanical model with test data [2] for the initiation of unstable growth, the size of spallation and kinking off.

\begin{tabular}{|c|c|c|c|c|c|c|c|c|}
\hline & \multicolumn{3}{|c|}{$\left(R_{B}\right)_{U G}(\mu \mathrm{m})$} & \multicolumn{3}{|c|}{$\left(R_{B}\right)_{S P}(\mu \mathrm{m})$} & \multicolumn{2}{|c|}{$h / \tan (\beta)(\mu \mathrm{m})$} \\
\hline & Eq. (27) & Eq. (29) & Test data [2] & Eq. (40) & Eq. (41) & Test data [2] & Eq. (46) & Test data [2] \\
\hline Fig. 6a & 41.2 & 40.7 & 40.0 & 76.9 & 75.3 & 75.0 & 7.53 & 9.10 \\
\hline Fig. $6 b$ & 52.0 & 51.5 & 47.5 & 97.0 & 95.4 & 97.5 & 9.10 & - \\
\hline Fig. 6c & 68.1 & 67.6 & 67.5 & 127 & 125 & 123 & 12.0 & 13.5 \\
\hline
\end{tabular}

To test the validity of Eqs. (45) and (46), values of $h / \tan (\beta)$ are also recorded in Table 1. The test result of $9.10 \mu \mathrm{m}$ is measured approximately from Fig. $2 \mathrm{f}$ and is close to the value of $7.53 \mu \mathrm{m}$ given by Eq. (46). Note that the case in Fig. $2 \mathrm{f}$ is slightly different from the case in Fig. 6a: The residual stress in and the thickness of the $\alpha-\mathrm{Al}_{2} \mathrm{O}_{3}$ film in Fig. $2 \mathrm{f}$ are $\sigma_{0}=4.3 \mathrm{GPa}$ and $h=5 \mu \mathrm{m}$, respectively, whereas in Fig. 6a they are $\sigma_{0}=4.46 \mathrm{GPa}$ and $h=4.9 \mu \mathrm{m}$, respectively. The value $7.53 \mu \mathrm{m}$ in Table 1 is calculated for the case in Fig. $2 \mathrm{f}$. 
No test value for Fig. $6 \mathrm{~b}$ case was found in the studies [1,2]. The test value $13.46 \mu \mathrm{m}$ for Fig. $6 \mathrm{c}$ is measured approximately from Fig. $7 \mathrm{f}$ and is also close to the value of $12.0 \mu \mathrm{m}$ given by Eq. (46). To obtain the approximate test values, the averages of four measured diameters taken at $0^{\circ}, 90^{\circ}, \pm 45^{\circ}$ are used. Fig. 7 shows another sequence of optical images of the nucleation and growth of a separation bubble with time at room temperature leading to sudden spallation after $124 \mathrm{~min}$. The oxide thickness is about $8 \mu \mathrm{m}$ and the residual compressive stress measured far away from spalls is $4.3 \mathrm{GPa}$, which nearly equals $4.31 \mathrm{GPa}$ for the case in Fig. 6c. It is worth noting that both predicted values of $h / \tan (\beta)$ are smaller than the measured values. One possible reason may be that the PEC boundary slightly exceeds $\left(R_{B}\right)_{M U}$ resulting in further contribution to the kinetic energy. That is, the PEC energy is larger than $\left(U_{a}\right)_{M U}$. Its minimum value can be estimated as $2 \pi h G_{c f}\left(R_{B}\right)_{S P} / \sin (\beta)$.
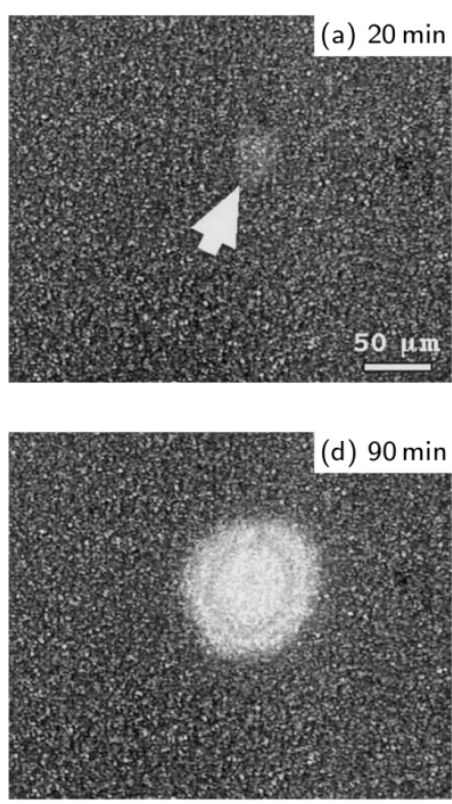
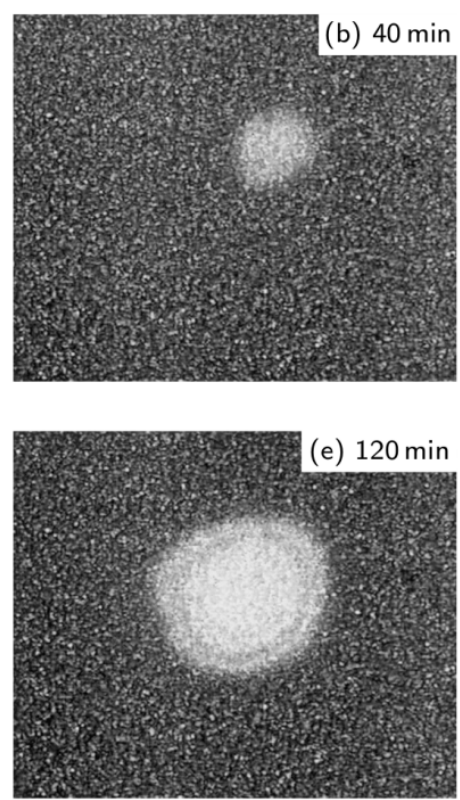
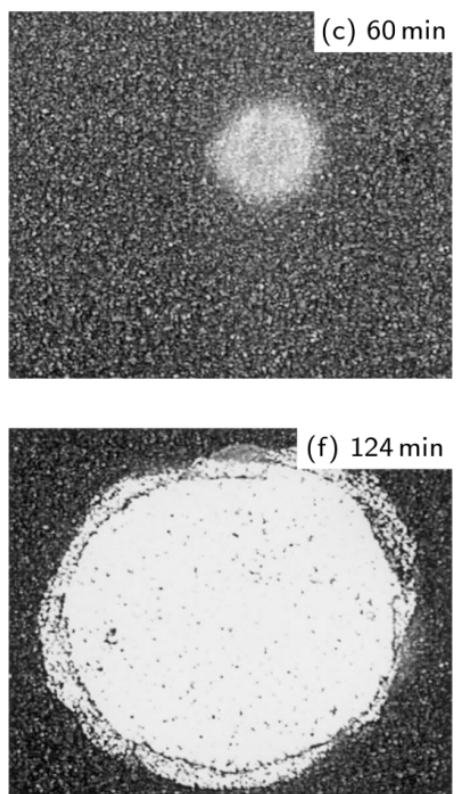

Fig. 7. A sequence of optical images showing the nucleation and growth of a separation bubble with time at room temperature leading to sudden spallation after $124 \mathrm{~min}$. The oxide thickness is $8.0 \mu \mathrm{m}$ and the residual compressive stress in the oxide measure far away from the bubble is $4.3 \mathrm{GPa}$. Reprinted with permission from Tolpygo, V.K., Clarke, D.R., 2000. Mater. Sci. Eng. A278, 151-161. Copyright 2000 Elsevier.

To further test the capability of Eq. (41) for the prediction of spallation size, more of the extensive test data in Ref. 2 is used for a second group of comparisons. A total of 23 specimens with different substrate thicknesses were oxidized in identical conditions for $25 \mathrm{~h}$ at $1200^{\circ} \mathrm{C}$ to produce an oxide thickness of $h=4.9 \mu \mathrm{m}$ and then cooled at different rates 
$\left(5^{\circ}-200^{\circ} \mathrm{C} \mathrm{min}^{-1}\right)$. The spallation radius $\left(R_{B}\right)_{S P}$ was measured on 50-60 circular spalls on each specimen and the corresponding residual compressive stress was probed in the adherent oxide far away from the spalls. All these measurements are gathered together in Fig. 8. The spallation radius, plotted as a function of residual compressive stress in the oxide, can indeed be described very well by Eq. (41), as shown by the top black solid curve. The middle gray dashed curve is from Eq. (35) for maximum bubble energy. The bottom black dashed curve is from Eq. (29) for the initiation of unstable growth.

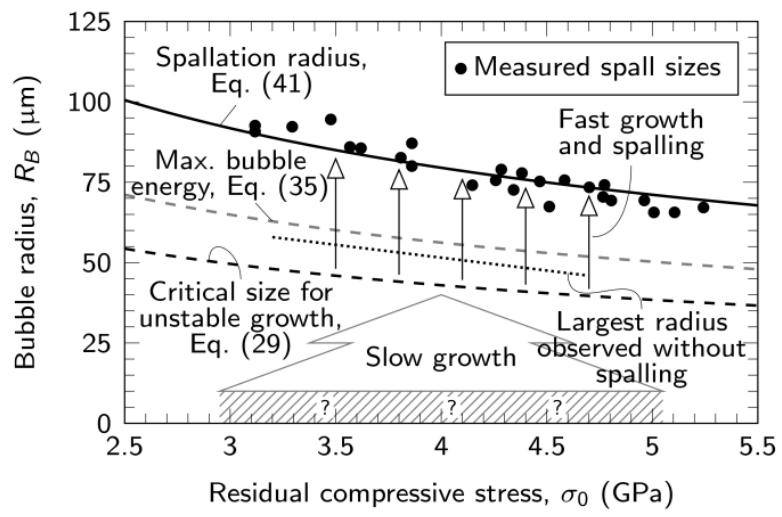

Fig. 8. Bubble growth behavior and spallation radius as a function of residual stress in the oxide for the same oxide thickness ( $h=4.9 \mu \mathrm{m}$ ).

The minimum size at which bubbles were first discerned is indicated by the bottom line of the large arrow labelled 'slow growth'. This line can be regarded as the nucleation stage with the nucleation PEC energy equal to $1.5 \pi R_{B}^{2} G_{c}$, as given by the first term of Eq. (25). It is seen that one third of the nucleation PEC energy is used to bend the separation outwards after nucleating the interface separation using two thirds of its energy. The hatched area with the question marks below the nucleation line corresponds to the range where nucleating bubbles could not be clearly resolved. Slow, stable growth occurs above the nucleation line, in the region indicated by the large arrow, and is driven solely by bubble energy. If the PEC cannot provide sufficient energy for growth, as given by Eq. (25), then the bubble will stop growing and becomes a stationary bubble.

The region between the bottom black dashed curve and the middle gray dashed curve is regarded as the first stage unstable growth, which is driven both by the bubble energy and by buckling. Although the growth rate is much faster than during stable growth it is still too slow to build up significant kinetic energy. The bubble, however, now changes to be a buckle. As before, if the PEC cannot provide the sufficient energy for growth, as given by Eq. (25), then 
the bubble will stop growing and becomes a stationary bubble. The black dotted line in this region shows the largest stationary buckles observed.

The region between the middle gray dashed curve and the top black solid curve is regarded as the second stage unstable growth. The bubble energy reaches its maximum value, given by Eq. (39), on the middle gray dashed curve. It is seen that the largest stationary buckles are always below the maximum bubble energy curve as expected. Above the maximum bubble energy curve, the sum of the bubble energy in Eq. (25) and the kinetic energy due to the violent growth will remain constant if the PEC boundary ends at $\left(R_{B}\right)_{M U}$. At the spallation radius, given by Eq. (40) or (41), the bubble energy in Eq. (25) becomes zero and further crack propagation along the interface is not possible. At this point, if the kinetic energy of the propagating bubble, which is estimated to be the maximum bubble energy as given by Eq. (39), is not large enough to crack the oxide film, a stationary spall is produced. If, however, the kinetic energy is large enough to break the oxide film, that is, Eq. (45) is satisfied, spallation or kinking off occurs.

It is worth noting that Ref. 37 extends the present study to, firstly, consider straight-edged spallation driven by PECs; and to, secondly, develop mechanical models for PEC-driven spallation based on the classical plate theory partition theory $[15,16]$ and the first-order sheardeformable plate partition theory $[15,16]$ for both straight-edged and circular-edged spallation.

\section{Conclusions}

The present mechanical model, based on the PEC hypothesis, predicts very well several aspects of the room temperature failure of $\alpha$-alumina films grown by oxidation, including the initiation of unstable growth, and the size of spallation or kinking off. For a bubble to nucleate, the PEC needs to provide energy equal to $1.5 \pi R_{B}^{2} G_{c}$ as seen from Eq. (25) and the explanations immediately below Eq. (25). Eq. (25) and the subsequent explanations show that one third of this energy is used to bend the separation outwards to form a bubble after nucleating the interface separation using two thirds of its energy. Stable growth of the bubble is then driven by the bubble energy. The bubble becomes a buckle at a critical radius of $R_{B}=0.5 \alpha \pi h / \sqrt{3 \bar{\varepsilon}_{0}}$ from Eq. (29) at which point unstable growth starts, driven both by the bubble energy and by buckling. The bubble energy reaches its maximum value at $R_{B}=0.5 \pi h / \sqrt{2 \bar{\varepsilon}_{0}}$ from Eq. (35) with energy equal to $0.75 \pi R_{B}^{2} G_{c}$ from Eq. (39). The 
spallation radius is $R_{B}=0.5 \pi h / \sqrt{\bar{\varepsilon}_{0}}$ from Eq. (41). At this radius, the spallation will kink off if the maximum bubble energy, that is, $0.75 \pi R_{B}^{2} G_{c}$ from Eq. (39), is large enough to break the oxide film.

The present mechanical model reveals a new failure mechanism of thin films under compressive residual stress. This failure mechanism might occur in other situations such as in thermal barrier coating material systems. Indeed, the first two authors are currently applying the model to the spallation of thermal barrier coating systems and the preliminary results are encouraging. Moreover, the model has already been extended to telephone cord buckling driven by PECs $[38,39]$. The present model could also be used in conjunction with experimental results to determine the material properties of a film-substrate material system, such as the Young's modulus, the fracture toughness of the thin film, and the interface fracture toughness.

\section{Acknowledgements}

The authors gratefully acknowledge Professor D. R. Clarke of Harvard University for valuable discussions.

\section{References}

[1] Tolpygo VK, Clarke DR. Spalling failure of $\alpha$-alumina films grown by oxidation: I. Dependence on cooling rate and metal thickness. Mater. Sci. Eng. 2000;A278:142-50. DOI: 10.1016/S0921-5093(99)00581-X.

[2] Tolpygo VK, Clarke DR. Spalling failure of $\alpha$-alumina films grown by oxidation. II. Decohesion nucleation and growth. Mater. Sci. Eng. 2000;A278:151-61. DOI: 10.1016/S0921-5093(99)00582-1.

[3] Hutchinson JW, He MY, Evans AG. The influence of imperfections on the nucleation and propagation of buckling driven delaminations. J. Mech. Phys. Solids 2000;48:70934. DOI: 10.1016/S0022-5096(99)00050-2.

[4] He MY, Evans AG, Hutchinson JW. Effects of morphology on the decohesion of compressed thin films. Mater. Sci. Eng. 1998;A245:168-81. DOI: 10.1016/S09215093(97)00848-4.

[5] Gaudette F, Suresh S, Evans AG, Dehm G, Rühle M. The influence of chromium addition on the toughness of $\gamma$-Ni $\alpha$-Al2O3 interfaces. Acta Mater. 1997;45:3503-13. DOI: 10.1016/S1359-6454(97)00064-5.

[6] Zhu C, Zhao X, Molchan IS, Thompson GE, Liang G, Xiao P. Effect of cooling rate and substrate thickness on spallation of alumina scale on Fecralloy. Mater. Sci. Eng. 2011;A528: 8687-93. DOI: 10.1016/j.msea.2011.08.044.

[7] Yu HH, He MY, Hutchinson JW. Edge effects in thin film delamination. Acta. Mater. 2001;49:93-107. DOI: 10.1016/S1359-6454(00)00293-7. 
[8] Harvey CM. Mixed-mode partition theories for one-dimensional fracture. $\mathrm{PhD}$ thesis, University of Loughborough, England, UK; 2012.

URL: https://dspace.lboro.ac.uk/2134/10269.

[9] Koenig SP, Boddeti NG, Duan ML, Bunch JS. Ultrastrong adhesion of graphene membranes. Nat. Nanotechnol. 2011;6:543-6. DOI: 10.1038/nnano.2011.123.

[10] Yue K, Wei G, Huang R, Liechti KM. Analytical methods for the mechanics of graphene bubbles. J. Appl. Phys. 2012;112:083512. DOI: 10.1063/1.4759146.

[11] Zong Z, Chen CL, Dokmeci MR, Wan KT. Direct measurement of graphene adhesion on silicon surface by intercalation of nanoparticles. J. Appl. Phys. 2010;107:026104. DOI: $10.1063 / 1.3294960$.

[12] Harvey CM, Wang S. Experimental assessment of mixed-mode partition theories. Compos. Struct. 2012;94:2057-67. DOI: 10.1016/j.compstruct.2012.02.007.

[13] Harvey CM, Eplett MR, Wang S. Experimental assessment of mixed-mode partition theories for generally laminated composite beams. Compos. Struct. 2015;124:10-8. DOI: 10.1016/j.compstruct.2014.12.064.

[14] Wang S, Harvey CM, Wang B, Watson A. Post-local buckling-driven delamination in bilayer composite beams. Compos. Struct. 2015;133:1058-66.

DOI: 10.1016/j.compstruct.2015.08.012.

[15] Wang S, Harvey CM. Mixed mode partition theories for one dimensional fracture. Eng. Fract. Mech. 2012;79:329-52. DOI: 10.1016/j.engfracmech.2011.11.013.

[16] Harvey CM, Wang S. Mixed-mode partition theories for one-dimensional delamination in laminated composite beams. Eng. Fract. Mech. 2012;96:737-59.

DOI: 10.1016/j.engfracmech.2012.10.001.

[17] Hutchinson JW, Suo Z. Mixed mode cracking in layered materials. Adv. Appl. Mech. 1991;29:63-191. DOI: 10.1016/S0065-2156(08)70164-9.

[18] Harvey CM, Wood JD, Wang S, Watson A. A novel method for the partition of mixedmode fractures in 2D elastic laminated unidirectional composite beams. Compos. Struct. 2014;116:589-94. DOI: 10.1016/j.compstruct.2014.05.041.

[19] Wood JD, Harvey CM, Wang S. Partition of mixed-mode fractures in 2D elastic orthotropic laminated beams under general loading. Compos. Struct. 2016;149:239-46. DOI: 10.1016/j.compstruct.2016.04.016.

[20] Wood JD, Harvey CM, Wang S. Adhesion toughness of multilayer graphene membranes. 2016. Manuscript in preparation.

[21] Williams ML. The stresses around a fault or crack in dissimilar media. B. Seismol. Soc. Am. 1959;49:199-204.

[22] Dattaguru B, Venkatesha KS, Ramamurthy TS, Buchholz FG. Finite element estimates of strain energy release rate components at the tip of an interface crack under mode I loading. Eng. Fract. Mech. 1994;49:451-63. DOI: 10.1016/0013-7944(94)90273-9.

[23] Hemanth D, Shivakumar Aradhya KS, Rama Murthy TS, Govinda Raju N. Strain energy release rates for an interface crack in orthotropic media-a finite element investigation. Eng. Fract. Mech. 2005;72:759-72.

DOI: 10.1016/j.engfracmech.2004.06.002.

[24] Krueger R. Virtual crack closure technique: History, approach, and applications. Appl. Mech. Rev. 2004;57:109-43. DOI: 10.1115/1.1595677. 
[25] Mantič V, París F. Relation between SIF and ERR based measures of fracture mode mixity in interface cracks. Int. J. Fract. 2004;130:557-69.

DOI: 10.1023/B:FRAC.0000049496.77533.d5.

[26] Raju IS, Crews Jr JH, Aminpour MA. Convergence of strain energy release rate components for edge-delaminated composite laminates. Eng. Fract. Mech. 1988;30:383-96. DOI: 10.1016/0013-7944(88)90196-8.

[27] Sun CT, Jih CJ. On strain energy release rates for interfacial cracks in bi-material media. Eng. Fract. Mech. 1987;28:13-20. DOI: 10.1016/0013-7944(87)90115-9.

[28] Sun CT, Qian W. The use of finite extension strain energy release rates in fracture of interfacial cracks. Int. J. Solids Struct. 1997;34:2595-609. DOI: 10.1016/S00207683(96)00157-6.

[29] Toya M. On mode I and mode II energy release rates of an interface crack. Int. J. Fract. 1992;56:345-52. DOI: 10.1007/BF00015864.

[30] Suo Z, Hutchinson JW. Interface crack between two elastic layers. Int. J. Fract. 1990;43:1-18. DOI: 10.1007/BF00018123.

[31] Harvey CM, Wood JD, Wang S. Brittle interfacial cracking between two dissimilar elastic layers: Part 1-Analytical development. Compos. Struct. 2015;134;1076-86. DOI: 10.1016/j.compstruct.2015.06.080.

[32] Harvey CM, Wood JD, Wang S. Brittle interfacial cracking between two dissimilar elastic layers: Part 2-Numerical verification. Compos. Struct. 2015;134;1087-94. DOI: 10.1016/j.compstruct.2015.06.079.

[33] Wood JD, Harvey CM, Wang S. Effect of Poisson's ratio on brittle interfacial cracking between two dissimilar elastic layers. Compos. Struct. 2016;158;56-63.

DOI: 10.1016/j.compstruct.2016.09.024.

[34] Nurmi E, Wang G, Kokko K, Vitos L. Assessing the elastic properties and ductility of $\mathrm{Fe}-\mathrm{Cr}-\mathrm{Al}$ alloys from ab initio calculations. Philos Mag A. 2016;96;122-33. DOI: 10.1080/14786435.2015.1119906.

[35] Timoshenko SP, Gere JM. Theory of elastic stability. 2nd ed. New York: McGraw-Hill; 1963.

[36] Fleck NA, Cocks ACF, Lampenscherf J. Thermal shock resistance of air plasma5sprayed thermal barrier coatings. J. Eur. Ceram. Soc. 2014;34:2687-94. DOI: 10.1016/j.jeurceramsoc.2014.01.002.

[37] Harvey CM, Wang B, Wang S. Spallation of thin films driven by pockets of energy concentrations. 2016. Manuscript submitted for publication.

[38] Wang S, Harvey CM. The mechanics of interface fracture. In: Proc of the 14th International Conference on Fracture. Rhodes, Greece: 2017. A plenary lecture.

[39] Yuan B, Harvey CM, Thomson RC, Critchlow GW, Wang S. Telephone cord buckling of thin films driven by pockets of energy concentration. Unpublished results. 